\title{
Penggolongan Equipment Critically Rating Dan Proses Expand Pada Exchanger E-5503 Di Pabrik III PT Petrokimia Gresik
}

\section{Classification Equipment Critically Rating and Process Expand on Exchanger E- 5503 at the Factory III PT Petrokimia Gresik}

\author{
Muhammad Rizal $^{1}$, R. Fairuz Zamani ${ }^{2}$ Novi Sukma Drastiawati ${ }^{3}$ \\ 1,3 Muhammad Rizal, Novi Sukma Drastiawati (Teknik Mesin/D-3 Produksi, Universitas Negeri Surabaya) \\ ${ }^{1}$ muhammadrizal16050423007@mhs.unesa.ac.id \\ 3novidrastiawati@unesa.ac.id \\ ${ }^{2}$ Petrokimia Gresik, Indonesia \\ ${ }^{2}$ fairuz.zamani@petrokimia-gresik.com
}

\begin{abstract}
Abstrak - Penggolongan Equipment Critically Rating melalui penggunaan metode pendekatan resiko (dampak dan peluang) dalam penentuan ECR dapat menurunkan peralatan kritis dengan metode sebelumnya. Nilai Safety, Healty, and Environment didapat dari wawancara ke operator peralatan atau mesin. Nilai Production lost didapatan dari data sort maintenance tahun 2010, 2012, 2013, 2014, 2015, 2016, 2017. Nilai Maintenance Cost didapat dari total biaya yang dihabiskan untuk perbaikan peralatan atau mesin. Nilai Peluang didapat dari berapa kali peralatan atau mesin mati dalam waktu 7 tahun terakhir.

Proses Expand meliputi Gun Expand, digunakan untuk memberi tekanan terhadap benda kerja serta bisa diukur dan diatur amperenya yang dihubungkan ke ampere controller, Voltage Controller, berfungsi untuk penyearah dari sumber listrik ke ampere controller yang kemudian di hubungkan ke gun expand. Ampere Controller, digunakan untuk mengatur masuknya ampere yang masuk ke gun expand yang akan memberi tekanan terhadap benda kerja.
\end{abstract}

Kata Kunci- ECR, Expand, maintenance.

\footnotetext{
Abstract- Classification of Equipment Critically Rating through the use of risk approach methods (impact and opportunity) in determining ECR can reduce critical equipment by the previous method. Value of Safety, Healty, and Environment is obtained from interviews with equipment or machine operators. Production value was lost from data sort maintenance in 2010, 2012, 2013, 2014, 2015, 2016, 2017. The value of Maintenance Cost is derived from the total costs spent on repairing equipment or machinery. Value of Opportunity is obtained from the number of times the equipment or engine has been killed in the past 7 years.

Expand process includes Expand Gun, used to put pressure on the workpiece and can be measured and regulated amperage which is connected to the ampere controller, Voltage Controller, functions for rectifier from the power source to the ampere controller which is then connected to the expand gun. Ampere Controller, is used to adjust the entry of the ampere into the expand gun which will put pressure on the workpiece

Key Words - ECR, Expand, maintenance.
}

\section{Pendahuluan}

\section{A. Latar Belakang}

PT Petrokimia Gresik merupakan salah satu pabrik pupuk yang diharapkan mampu mendukung pemenuhan kebutuhan pupuk dan bahan kimia pertanian di Indonesia khususnya di Jawa Timur. Demi pemenuhan kebutuhan pupuk dibutuhkan peralatan ataupun mesin yang digunakan dalam produksi memiliki kecanggihan yang bisa membuat hasil produksi pupuk menjadi lebih baik dan memiliki nilai efisiensi yang tinggi, ini diharapkan mempunyai hasil kualitas pupuk yang cukup baik sehingga mampu memuaskan kebutuhan konsumen. (PT Petrokimia Gresik)

Tujuan utama dari setiap perusahaan adalah memperoleh keuntungan optimal dengan pemanfaatan sumber daya yang ada secara maksimal. Kegiatan produksi merupakan salah satu faktor penting di dalam pencapaian tujuan perusahaan. Produksi menurut Alam (2008) sendiri diartikan sebagai kegiatan yang dikerjakan untuk menambah nilai guna suatu benda atau menciptakan benda baru sehingga lebih bermanfaat dalam memenuhi kebutuhan. Apabila kegiatan produksi terhenti maka perusahhan bisa mengalami production lost. Sedemikian pentingnya kegiatan produksi di dalam suatu perusahaan sehingga tidak heran jika perusahaan-perusahaan akan selalu memperhatikan kegiatan produksi dalam perusahaan tersebut.

Salah satu faktor yang mendukung kelancaran kegiatan poduksi adalah penggunaan peralatan produksi. Dengan digunakannya peralatan-peralatan produksi untuk membantu kegiatan produksi maka target industri suatu perusahaanakan tercapai yaitu dapat memenuhi permintaan pasar dan konsumen. Peralatan produksi dalam perusahaan yang digunakan untuk proses produksi suatu produk akan digunakan dari hari ke hari tanpa mengenal istirahat, kecuali ada waktu khusus yang disediakan untuk 
mengadakan perawatan atau pemeliharaan kepada mesin dan peralatan produksi dalam perusahaan tersebut. Penggunaaan mesin dalam kegiatan produksi yang berlangsung terus - menerus pada jangka waktu tertentu dapat mengalami kerusakan. Hal tersebut tentunya akan berakibat pada terhambatnya kegiatan produksi.

Demi menjaga kinerja mesin dan peralatan produksi tetap baik maka pelaksaan pemeliharaan dan perawatan juga harus diperhatikan agar kegiatan produksi tidak terganggu. Meskipun begitu sering kali kegiatan maintenance di dalam suatu perusahaan terabaikan, sehingga terjadilah kegiatan pemeliharaan yang tidak teratur. Maintenance dapat diartikan sebagai kegiatan untuk memelihara dan menjaga fasilitas atau peralatan produksi dan mengadakan perbaikan yang diperlukan agar operasional pabrik dapat menghasilkan produk dengan sesuai target yang ditentukan (kuantum dan kualitas). (Supandi, 1990)

Kegiatan pemeliharaan (maintenance) meliputi perencanaan, perbaikan pengawasan, penggantian suku cadang dan improvement kehandalan. Selain itu, peranan perawatan mesin sangat penting untuk menjaga agar produksi berjalan dengan baik dan lancar sehingga terhindar dari kemungkinan kerusakan mesin, menurunnya produktivitas jam kerja dan biaya perawatan yang tinggi. Pada dasarnya yang diharapkan dari beberapa mesin tidak lain untuk meningkatkan efektifitas serta porsi keuntungan bagi perusahaan. Oleh karena itu penggunaan mesin produksi tidak terlepas dari adanya pemeliharaan yang menjaga agar mesin produksi agar tetap terus dapat berjalan dan menjaga kestabilan produksi.

Dari penjelasan diatas dapat disimpulkan penulis perlu melakukan Praktik Industri (PI) guna memahami permasalahan di dunia industri khususnya dibidang produksi serta maintenance secara langsung dikarenakan penulis hanya mendapat pengetahuaan teoritis dari perkuliahan. Setelah penulis melakukan praktik industri penulis mengangkat judul "Penggolongan Equipment Critically Rating (ECR) dan Proses Expand pada Heat Exhanger E-5503 di Pabrik III PT. Petrokimia Gresik". Dengan ini penulis diharapkan bisa memahami apa aja proses maintenance yang ada di Petrokimia Gresik ksususnya pada pabrik III. Sehingga bisa memahami proses maintenance dalam sebuah industri yang sebelumnya belum diperoleh dalam proses perkuliahan.

\section{KAJIAN PUSTAKA}

A. Penjelasan Umum Maintenance

Menurut Supandi (1990) dalam Dholpina (2011), maintenance adalah kegiatan atau aktivitas untuk menjaga, memperbaiki atau mempertahankan kualitas peralatan dan mesin agar berjalan dengan baik seperti kondisi sebelumnya. Sedangkan maintenance menurut Barry (2001) dalam Djunaidi (2012), maintenance diperlukan untuk mempertahankan kualitas dan meningkatkan produktivitas sehingga maintenance merupakan hal penting yang harus diperhatikan.

Berdasarkan pendapat dari definisi dapat disimpulkan bahwa maintenance merupakan suatu kegiatan untuk merawat, memperbaiki suatu komponen mesin agar mesin atau peralatan dapat mempertahankan kualitas dan meningkatkan produktivitas secara aman, efektif, dan efisien sesuai yang telah direncanakan. Tujuan dari pelaksanaan kegiatan maintenance menurut Assauri (2013) dalam Dholpina (2011) sebagai berikut:

1. Mempertahankan kemampuan produksi sesuai dengan rencana produksi.

2. Menjaga kualitas produksi serta kegiatan produksi tidak terganggu.

3. Membantu mengurangi biaya yang diluar batas selama waktu yang tidak ditentukan sesuai dengan kebijakan perusahaan.

4. Menerapkan kegiatan maintenance yang efektif dan efisien sehingga dapat meminimaliasir biaya.

5. Menghindari kegiatan maintenance yang membahayakan karyawan.

6. Mencapai tujuan umum perusahaan dengan mengadakan kerja sama yang baik dalam fungsifungsi yang lain dalam perusahaan.

Maintenance dalam suatu perusahaan sangat penting, hal tersebut karena permasalahan dalam maintenance menyangkut semua peralatan dalam perusahaan. Maintenance yang dilakukan oleh setiap perusahaan berbeda-beda. Menurut Dholpina (2011), maintenance dikelompokkan menjadi 2 yaitu preventive maintenance dan corrective maintenance :

\section{Preventive maintenance}

Maintenance preventive atau preventive maintenance merupakan kegiatan maintenance yang bertujuan mencegah terjadinya suatu kerusakan atau cara maintenance yang direncanakan untuk pencegahan seperti inspeksi, perbaikan kecil, pelumasan dan penyetelan. Maintenance tersebut dilakukan agar mesin atau peralatan yang beroperasi dapat terhindar dari kerusakan. Maintenance preventive sangat penting diterapkan pada perusahaan yang proses produksinya kontinyu. Keuntungan program preventif yang baik jika dilakukan perusahaan menurut Supandi (1990) dalam Dholpina (2011) adalah:

a. Downtime waktu berkurang.

b. Kerja lembur untuk tenaga maintenance berkurang.

c. Waktu menunggu peralatan yang dibutuhkan berkurang.

d. Pengeluaran biaya perbaikan berkurang. 
e. Dapat menghemat penggantian suku cadang.

f. Kerusakan berkurang sehingga keselamatan kerja operator meningkat.

\section{Corrective maintenance}

Maintenance korektif atau corrective maintenance merupakan kegiatan maintenance yang dilakukan untuk memperbaiki dan meningkatkan kondisi peralatan atau mesin sehingga dapat kembali digunakan sesuai standar mesin. Maintenance korektif berupa tindakan penggantian atau perbaikan terhadap mesin yang mengalami kerusakan atau tidak dapat berfungsi dengan baik. Maintenance korektif bersifat menunggu sampai kerusakan terjadi baru dilakukan perbaikan.

B. Penjelasan Umum ECR

ECR (Equipment Critically Rating) merupakan sistem penilaian kekritisan peralatan berdasar pada resiko terhadap produksi dan safety jika peralatan tersebut gagal. (Tarel PT Petrokimia Gresik)

Berikut parameter ECR, yaitu parameter dampak, parameter peluang, dan kategori ECR :

1. Parameter Dampak

a. Insignificant

Sumber risiko (komponen atau obyek dalam beraktivitas) tidak berdampak sama sekali, akibatnya tidak signifikan terhadap kelangsungan aktivitas, sehingga aktivitas tetap terlaksana.

b. Minor

Sumber risiko (komponen atau obyek dalam beraktivitas) berdampak kecil, akibatnya kecil terhadap kelangsungan aktivitas, sehingga aktivitas masih terlaksana.

\section{c. Moderate}

Sumber risiko (komponen atau obyek dalam beraktivitas) berdampak sedang, akibatnya sedang terhadap kelangsungan aktivitas, sehingga aktivitas masih dapat terlaksana.

\section{d. Major}

Sumber risiko (komponen atau obyek dalam beraktivitas) berdampak besar, akibatnya cukup signifikan terhadap kelangsungan aktivitas, namun masih dapat terlaksana.

e. Catastrophic

Sumber risiko (komponen atau obyek dalam beraktivitas) berdampak sangat besar terhadap finansial perusahaan, akibatnya sangat signifikan terhadap kelangsungan aktivitas, sama sekali tidak dapat terlaksana.

2. Parameter Peluang

a. Rare

Apabila kondisi dan sumber risiko (komponen atau obyek dalam beraktivitas) kemungkinan terjadinya sangat kecil (rare) atau sekitar $0-10 \%$

b. Unlikely
Apabila kondisi dan sumber risiko (komponen atau obyek dalam beraktivitas) kemungkinan terjadinya sekali-kali (unlikely) atau sekitar $>10-30 \%$

\section{c. Moderate}

Apabila kondisi dan sumber risiko (komponen atau obyek dalam beraktivitas) kemungkinan terjadinya sekali-kali (unlikely) atau sekitar $>30-50 \%$

\section{d. Likely}

Apabila kondisi dan sumber risiko (komponen atau obyek dalam beraktivitas) kemungkinan terjadinya sering (likely) atau sekitar $>50-70 \%$

\section{e. Certain}

Apabila kondisi dan sumber risiko (komponen atau obyek dalam beraktivitas) kemungkinan hamper selalu atau pasti terjadi (certain) atau sekitar $>70 \% 2$ parameter dari ECR, yaitu parameter dampak dan parameter prluang. (Tarel PT Petrokimia Gresik)

3. Kategori ECR

Kategori Equipment Criticaly Rating dibagi menjadi 4 kategori, yaitu :

a. Kategori $\mathrm{C}=$ nilai $1-3$

b. Kategori $\mathrm{B}=$ nilai $4-12$

c. Kategori $\mathrm{A}=$ nilai $15-25$, dan semua nilai Dampak $=$ 5

d. Kategori L = peralatan yang terkait regulasi dan lingkungan

Dari perhitungan yang didapat selanjutnya digolongkan dengan kategori mana peralatan yang akan lebih diprioritaskan untuk dilakukan pemantauan kehandalannya. Peralatan yang akan dimonitoring kehandalannya diprioritaskan Peralatan yang memiliki indeks kekritisan kategori A. (Tarel PT Petrokimia Gresik)

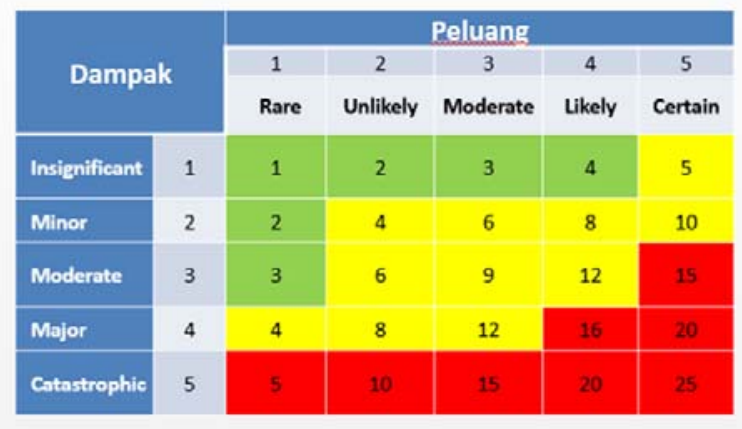

Gambar 2.1 Matrix ECR

(Sumber : Tarel PT Petrokimia Gresik) 


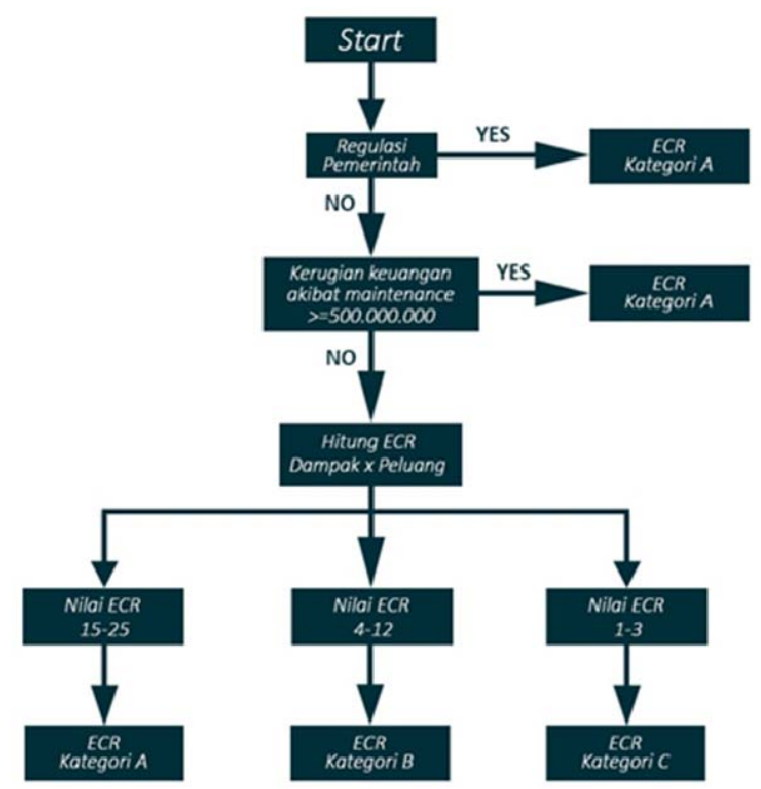

(Sumber : Tarel PT Petrokimia Gresik)

\section{PENILAIAN KOMPONEN KRITIS (ECR)}

Penilaian komponen kritis atau yang biasa disebut dengan ECR (Equipment Critically Rating) adalah suatu metode yang digunakan untuk mengetahui nilai kekritisan dari peralatan sehingga hasil penilaiannya dapat dijadikan input pada perencanaan sistem perawatan. Berdasarkan hasil ECR ini diharapkan dapat dilakukan perencanaan perawatan yang sistematis dan optimal berdasarkan skala prioritas dari ECR. (Tarel PT Petrokimia Gresik)

Nilai ECR didapat dari hasil analisa nilai dampak dikalikan dengan Peluang terjadinya breakdown. Nilai dampak adalah nilai tertiggi dari 3 kategori penilaian (Safety Factor, Production Lost, dan Maintenance Cost), sedangkan nilai peluang didapat dari seberapa sering mesin atau peralatan mengalami kegagalan fungsi atau breakdown. Penilaian ECR menggunakan pendekatan multi kriteria dengan kriteria sebagai berikut :

\section{Keamanan (Safety Factor)}

Penilaian keamanan dari suatu equipment didapat dari wawancara dengan operator produksi yang berkaitan dengan peralatan secara langsung, sehingga data yang dihasilkan merupakan data yang valid. Nilai keamanan ini berkaitan dengan seberapa berbahaya yang diakibatkan kepada operator produksi jika terjadi kegagalan fungsi peralatan, atau juga dengan keamanan lingkungan, apakah akan berdampak buruk bagi lingkungan perusahaan dan masyarakat sekitar sehingga dapat berpengaruh terhadap nama baik perusahaan.

Tabel 2.1 safety, healty, dan environment

\begin{tabular}{|c|l|}
\hline NILAI & \multicolumn{1}{|c|}{ Safety, Healty, dan Environment } \\
\hline 1 & $\begin{array}{l}\text { Tidak menimbulkan kecelakaan kerja } \\
\text { dan lingkungan }\end{array}$ \\
\hline 2 & $\begin{array}{l}\text { Menimbulkan kecelakaan kerja ringan, } \\
\text { korban sadar, lingkungan }\end{array}$ \\
\hline 3 & $\begin{array}{l}\text { Menimbulkan kecelakaan kerja ringan, } \\
\text { korban tidak sadar }\end{array}$ \\
\hline 4 & Menimbulkan kecelakaan kerja berat \\
\hline 5 & $\begin{array}{l}\text { Menimbulkan kecelakaan kerja korban } \\
\text { jiwa }\end{array}$ \\
\hline
\end{tabular}

\section{Faktor Produksi (Production Lost)}

Bila suatu alat atau peralatan terjadi kegagalan fungsi sehingga harus dilakukan perbaikan, maka hal itu akan berdampak terhadap sistem proses produksi di dalam pabrik, hal ini dapat menyebabkan kerugian bagi perusahaan karena tidak dapat melakukan kegiatan produksi. Perhitungan nilai production lost diambil dari lamanya suatu peralatan berhenti dalam setahun.

Tabel 2.2 Production Lost
\begin{tabular}{|c|c|}
\hline NILAI & PRODUCTION LOST \\
\hline 1 & Downtime $<1$ hari \\
\hline 2 & Downtime 1-2 hari \\
\hline 3 & Downtime $2,01-3$ hari \\
\hline 4 & Downtime 3,01-4 hari \\
\hline 5 & Downtime $>4$ hari \\
\hline
\end{tabular}

(Sumber : Tarel PT Petrokimia Gresik)

\section{Maintenance Cost}

Perbaikan suatu mesin di perusahaan dapat mengeluarkan biaya yang besar dan merugikan perusahaan, oleh karena itu, perusahaan akan berusaha secara optimal guna menurunkan pengeluaran akibat maintenance.

Tabel 2.3 Maintenance Cost

\begin{tabular}{|c|c|}
\hline NILAI & MAINTENANCE COST \\
\hline 1 & $<=50.000 .000$ \\
\hline 2 & $<=100.000 .000$ \\
\hline 3 & $<=200.000 .000$ \\
\hline 4 & $<500.000 .000$ \\
\hline 5 & $>=500.000 .000$ \\
\hline
\end{tabular}

(Sumber : Tarel PT Petrokimia Gresik) 


\section{Peluang (Frekuensi kegagalan)}

Frekuensi kegagalan diperoleh dari data catatan historis mesin selama 7 tahun terakhir.

Tabel 2.4 Peluang

\begin{tabular}{|c|c|}
\hline NILAI & PELUANG \\
\hline 1 & 10 tahun sekali \\
\hline 2 & 1 tahun sekali \\
\hline 3 & 3 bulan sekali \\
\hline 4 & 1 bulan sekali \\
\hline 5 & 1 minggu sekali \\
\hline
\end{tabular}

(Sumber : Tarel PT Petrokimia Gresik)

\section{A. Definisi Heat Exchanger}

Menurut Incropera dan Dewitt (1981), efektivitas suatu heat exchanger didefinisikan sebagai perbandingan antara perpindahan panas yang diharapkan (nyata) dengan perpindahan panas maksimum yang mungkin terjadi dalam heat exchanger tersebut. Secara umum pengertian alat penukar panas atau heat exchanger (HE), adalah suatu alat yang memungkinkan terjadinya perpindahan panas dan bisa berfungsi sebagai pemanas maupun sebagai pendingin.

HE (heat exchanger) merupakan salah satu jenis dari PV (pressure vessel), yang juga didefinisikan sebagai suatu peralatan yang digunakan untuk menukarkan energi dalam bentuk panas antara fluida yang berbeda temperatur yang dapat terjadi melalui kontak langsung maupun secara kontak tidak langsung. Fluida yang bertukar energi dapat berupa fluida yang sama fasanya (cair ke cair atau gas ke gas) atau dua fluida yang berbeda fasanya. Biasanya medium pemanas memakai uap panas (super heated steam) dan air bersuhu ruang sebagai media pendingin (cooling water). Alat penukar panas dirancang sebisa mungkin agar perpindahan panas antar fluida dapat berlangsung secara efisien.

Heat exchanger umumnya digunakan untuk memindahkan energi panas antara dua atau lebih fluida dan terjadi pada temperatur yang berbeda antara fluida, dimana fluida tersebut ada yang bertindak sebagai fluida panas (hot fluid) dan yang lain bertindak sebagai fluida dingin (cold fuild). Bidang perpindahan panas ini umumnya berupa dinding pipa-pipa atau sirip-sirip yang dipasangkan pada pipa (fin).

Kalor dapat dipindahkan diantara kedua fluida tersebut, besarnya sangat tergantung pada kecepatan aliran fluida, arah alirannya, sifat-sifat fluida, kondisi permukaan dan luas bidang perpindahan panas serta beda temperatur diantara kedua fluida. Fluida yang mengalir didalam heat exchanger kadang-kadang mengandung zatzat yang mengendap atau menggerak pada permukaan pipa atau bereaksi dan menyebabkan korosi atau kerusakan lainnya, sehingga herformansi heat exchanger dapat menjadi turun.

Pada dasarnya heat exchanger terdiri dari tubetube (tube bundels) yang dipasang didalam shell yang berbentuk silinder. Berfungsi untuk menukar panas dari 2 jenis fluida yang mengalir secara terpisah melalui sisi tube dan sisi shell. Keduanya dihubungkan dengan dudukan yang disebut tube sheets, yang juga berfungsi untuk memisahkan fluida yang mengalir disisi shell dan didalam tube.

Didalam dunia industri proses kimia perpindahan energi atau panas adalah hal yang banyak dilakukan. Sebagaimana diketahui bahwa panas dapat berlangsung lewat tiga cara, dimana mekanisme perpindahan panas itu sendiri berlainan adanya. Adapun perpindahan panas itu dilaksanakan dengan:

1) Secara molekuler

Perpindahan panas secara molekuler disebut dengan konduksi. Secara molekuler dimana dalam mekanisme ini digerakkan oleh suatu molekul yang berada pada tingkat energi (temperatur) yang lebih tinggi dan memberikan energi ke molekul-molekul didekatnya yang berada pada tingkat energi yang lebih rendah.

2) Secara aliran

Perpindahan panas secara aliran disebut perpindahan konveksi. Transfer panas yang disebabkan secara konveksi melibatkan pertukaran energi antara suatu permukaaan dengan fluida didekatnya.

3) Secara Gelombang Elektromagnetik

Perpindahan panas secara elektromagnet disebut dengan radiasi. Dimana Perpindahan panas tanpa melalui media (tanpa melalui molekul). Suatu energi dapat dihantarkan dari suatu tempat ke tempat lainnya (dari benda panas ke benda yang dingin) dengan pancaran gelombang elektromagnetik dimana tenaga elektromagnetik ini akan berubah menjadi panas jika terserap oleh benda yang lain.

Perusahaan-perusahaan dalam industri kimia memilih menggunakan heat exchanger karena memiliki beberapa keuntungan diantaranya:

1) Bentuknya baik untuk operasi yang bertekanan

2) Dapat dibuat dari berbagai jenis material yang disesuaikan dengan kondisi operasional dan fluida yang digunakan

3) Mudah dibersihkan

4) Teknik fabrikasi dan prosedur perencanaanya relatif mudah

Dikarenakan fluida yang digunakan pada heat exchanger ini adalah fluida yang bertekanan, maka pemilihan material logam atau logam paduan yang digunakan untuk pembuatan heat exchanger, khususnya pada bagian head, shell, tube, nozzle dan tube sheets harus benar-benar diperhatikan. Karena sifat dari masingmasing fluida dalam hal ini khusunya NH3 (amoniak) yang memiliki tekanan tinggi. (Incropera dan Dewitt,1981) 


\section{B. Prinsip Kerja Heat Exchenger}

Panas adalah salah satu bentuk energi yang dapat dipindahkan dari suatu tempat ke tempat lain yang dapat mengakibatkan terjadinya kenaikan suhu suatu zat atau perubahan tekanan, reaksi kimia dan kelistrikan.

Proses terjadinya perpindahan panas dapat dilakukan secara langsung, yaitu fluida yang panas akan bercampur secara langsung denagan fluida dingin tanpa adannya pemisahan secara langsung dan tidak langsung, yaitu bila diantara fluida panas dan fluida dingin tidak berhubungan langsung tetapi dipisahkan oleh sekat-sekat pemisah. (Incropera dan Dewitt,1981)

\section{Bagian-Bagian Heat Exchanger}

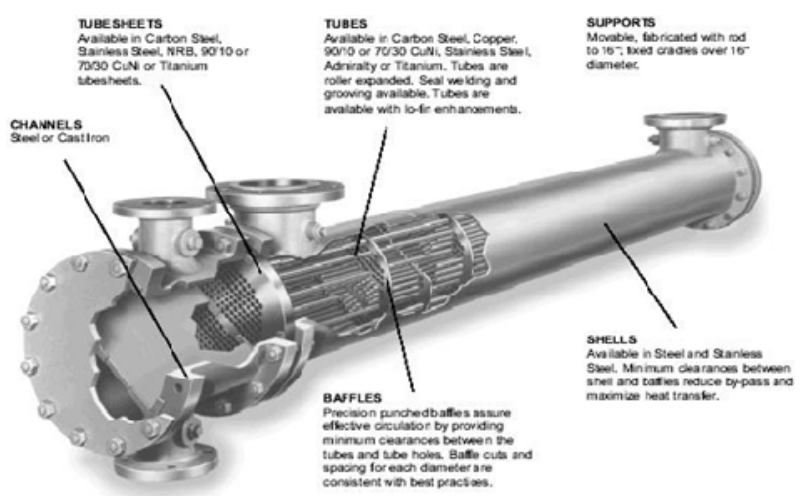

Gambar 2.3 Komponen Utama Heat Exchanger (Sumber : Hand Out Heat Exchanger Design Guide)

Secara keseluruhan komponen utama penyusun shell dan tube pada head exchanger adalah:

1. Head atau channel

Head berfungsi sebagai penutup shell yang berbentuk seperti pipa. Dan terdapat nozzle sebagai in-out fluida yang dipanaskan atau didinginkan.

2. Tube dan tubesheet

Tube merupakan pemisah dan sebagai pengantar panas yang berbeda suhunya diantara dua zat yang berada di dalam suatu alat. Tube sheet berfungsi sebagai tempat duduk tube bundle pada shell. Tube berada didalam flange yang sering disebut tube sheet. Pemilihan tube ini harus sesuai dengan suhu, tekanan, dan sifat korosi fluida yang mengalir. Karena tube dan tubesheet adalah bagian terpenting dan proses fabrikasinya juga memakan waktu paling lama diantara part lainnya.

a. Susunan Tube

Susunan tube akan mempengaruhi baik buruknya perpindahan panas. Pemilihan susunan tube harus dipertimbangkan dengan sistem perawatan dan bersih atau kotornya fluida yang mengalir dalam heat exchanger. Biasanya susunan tube, disusun dalam bentuk equilateral triangular, rotated triangular, dan square (rotated squared).

b. Laluan aliran didalam tube

Aliran didalam tube biasanya dibuat bolakbalik dalam sejumlah laluan untuk memperpanjang lintasan. Jumlah laluan juga dipilih untuk memberikan kecepatan aliran sesuai kebutuhan.

3. Flange

Flange berfungsi untuk menyambungkan shell dengan head yang dihubungkan dengan mur dan baut.

4. Shell

Shell berbentuk silinder dan sebagai tempat untuk proses pertukaran kalor dimana didalam shell terdapat tube-tube sebagai tempat mengalirnya fluida, dan nozzle sebagai fluida pemanas atau pendingin.

5. Tie rod dan spacer

Tie rod berbentuk ulir pada ujung-ujungnya, memiliki panjang sepanjang shell. Berfungsi sebagai penyangga baffle-baffle. Sedangkan spacer adalah pipa dimasukkan kedalam tie road. Spacer adalah pemisah atau pemberi jarak yang sudah ada dalam TEMA (tubular exchanger manufacturers association).

6. Baffle

Baffle atau sekat didalam shell digunakan untuk menahan dan mengurangi beban yang membentang sepanjang, dan juga untuk menaikkan kecepatan aliran fluida. Baffle atau sekat yang dipilih akan mempengaruhi besarnya penurunan tekanan, bentuk aliran, distribusi aliran dan lain-lain.

\section{Nozzle}

Sebagai tempat masuk keluarnya fliuda pada heat exchanger. Biasanya berjumlah empat buah, dua berada di head dan dua berada di shell.

8. Saddle

Sadlde berfungsi sebagai tempat dudukan bagi heat exchanger. (Hand Out Heat Exchanger Design Guide)

\section{Tube expand}

Tube expanding adalah sebuah proses deformasi yang dikerjakan dalam keadaan 'dingin', untuk mendapatkan kerapatan antara tube dengan lubang tube pada tube sheet. Dimana tube telah mencapai 'plastic' sedangkan tube sheet masih dalam tahap 'elastis'. (PT Petrokimia Gresik)

Proses expand berbeda untuk setiap materialnya dan memiliki spesifikasi khusus disetiap materialnya. Jika melebihi batas maksimum expand maka materialnya akan mengalami kerusakan. Contohnya sebagai berikut :

a. Stainlees steel 
4-5\% maximum expand untuk tube baru dan jika reexpand atau expand ulang barang lama bisa diatas 45\% maximum expand yang terjadi di lapangan.

b. Baja, baja karbon, kuningan

7-8\% maximum expand tube baru dan re-expand yang terjadi dilapangan $10 \%$ maximum expand.

c. Copper

8-9\% maximum expand untuk tube baru dan jika reexpand yang terjadi dilapangan sampai $12 \%$.

Proses expand juga memiliki perhitungan khusus yang menurut mekanik yang memperbaiki heat exchanger sudah memiliki standart ASME (American Society of Mechanical Enginer) yang berlaku sacara internasional. Berikut detail rumus yang digunakan untuk menghitung expand :

$D_{2}=\mathrm{K}\left(D_{\mathrm{G}}+D_{\mathrm{H}}\right)+\left(\mathrm{H}-D_{2}\right)+D_{\mathrm{H}}$

Dimana :

$\mathrm{K}=$ presentase maximum expand (ditentukan oleh bahan)

$D_{\mathrm{o}}=$ diameter out material

$D_{1}=$ diameter in material

$H=$ hole tube sheet

\section{E. Tujuan Expand}

Untuk memperoleh sebuah sambungan yang kencang atau rapat sehingga mencegah kebocoran dan tidak lepas dari dudukan, sambil meminimalkan stress corrosion serta retak (crack) secara axial pada zona transisi dibelakang tubesheet. Pada praktikum ini penulis melakukan expand terhadap exchanger pada pabrik III dengan kode exchanger E-5503.

\section{HASIL DAN PEMBAHASAN}

\section{A. Proses PengGolongan ECR}

ECR berbasis resiko merupakan kategori penggolongan berdasarkan pendekatan resiko (dampak dan peluang) yang dihadapi operator serta lingkungan saat peralatan mengalami kegagalan fungsi. Peralatan yang dianalisa penulis merupakan peralatan yang berada di pabrik PA1 functional location B000-B019-106-B0101 (Functloc) PT Petrokimia Gresik. Perbaruan nilai ECR ini dilakukan selama 5 tahun sekali. Nilai ECR yang sudah di perbarui dapat digunakan untuk rujukan prioritas work order (WO), untuk rujukan prioritas pengadaan barang, serta untuk prioritas pemantauan kehandalan peralatan.

Tahap-tahap dalam menentukan nilai ECR sebagai berikut :

a. Proses analisa nilai dampak

Nilai dampak disini merupakan nilai tertinggi dari 3 kategori (SHE, Production Lost, Maintenance Cost). Jika salah satu dari 3 kategori tersebut bernilai 5 , maka nilai dampak dari peralatan tersebut adalah 5 . dan jika kegagalan peralatan berdampak cukup besar terhadap lingkungan atau dapat merusak reputasi perusahaan maka nilai dampaknya adalah 5 .

1) Nilai Safety, Healty, dan Environment (SHE) Untuk mendapatkan nilai SHE, dilakukan wawancara terhadap pihak operator produksi yang berkaitan secara langsung dengan peralatan yang dianalisa. Pihak terkait akan diwawancarai mengenai kemungkinan resiko serta dampak terhadap operator dan lingkungan jika peralatan mengalami kegagalan fungsi.

Tabel 3.3 safety, healty, dan environment

\begin{tabular}{|c|l|}
\hline NILAI & \multicolumn{1}{|c|}{ Safety, Healty, dan Environment } \\
\hline 1 & $\begin{array}{l}\text { Tidak menimbulkan kecelakaan kerja } \\
\text { dan lingkungan }\end{array}$ \\
\hline 2 & $\begin{array}{l}\text { Menimbulkan kecelakaan kerja ringan, } \\
\text { korban sadar, lingkungan }\end{array}$ \\
\hline 3 & $\begin{array}{l}\text { Menimbulkan kecelakaan kerja ringan, } \\
\text { korban tidak sadar }\end{array}$ \\
\hline 4 & Menimbulkan kecelakaan kerja berat \\
\hline 5 & $\begin{array}{l}\text { Menimbulkan kecelakaan kerja korban } \\
\text { jiwa }\end{array}$ \\
\hline
\end{tabular}

(Sumber : Tarel PT Petrokimia Gresik)

2) Nilai Production Lost (PL)

Nilai production lost didapat dari data historis maintenance peralatan selama 7 tahun terakhir, nilai PL merupakan ratarata waktu mati atau peralatan ketika dalam kondisi perbaikan atau mati yang menyebabkan proses produksi terhenti.

Tabel 3.4 Production Loss

\begin{tabular}{|c|c|}
\hline NILAI & PRODUCTION LOST \\
\hline 1 & Downtime $<1$ hari \\
\hline 2 & Downtime 1-2 hari \\
\hline 3 & Downtime 2,01-3 hari \\
\hline 4 & Downtime 3,01-4 hari \\
\hline 5 & Downtime $>4$ hari \\
\hline
\end{tabular}

a) Nilai 1 jika terjadi downtime atau perbaikan peralatan kurang dari 1 hari.

b) Nilai 2 jika terjadi downtime atau perbaikan peralatan selama 1 sampai 2 hari. 
c) Nilai 3 jika terjadi downtime atau perbaikan peralatan selama 2.01 sampai 3 hari.

d) Nilai 4 jika terjadi downtime atau perbaikan peralatan selama 3.01 sampai 4 hari.

e) Nilai 5 jika terjadi downtime atau perbaikan peralatan selama lebih dari 4 hari.

Semua penilaian production lost didapat dari skala hari yang kemudian dibagi dengan jam.

3) Nilai Maintenance Cost (MC)

Nilai ini merupakan biaya yang dikeluarkan oleh perusahaan untuk perbaikan peralatan terkait. Data historis maintenance cost (7 tahun) didapat dari karyawan TAREL (TA dan Reabilitas) dari Departemen Pemeliharaan III.

Tabel 3.5 Maintenance Cost

\begin{tabular}{|c|c|}
\hline NILAI & MAINTENANCE COST \\
\hline 1 & $<=50.000 .000$ \\
\hline 2 & $<=100.000 .000$ \\
\hline 3 & $<=200.000 .000$ \\
\hline 4 & $<500.000 .000$ \\
\hline 5 & $>=500.000 .000$ \\
\hline
\end{tabular}

(Sumber : Tarel PT Petrokimia Gresik)

\section{b. Proses Analisa nilai peluang (frekuensi kegagalan)}

Dalam mencari nilai peluang penulis melakukan cek data historis (7 Tahun terakhir) maintenance dari peralatan terkait, lalu mulai merumuskan asumsi untuk disesuaikan kedalam nilai yang terdapat pada tabel peluang.

Tabel 3.6 Peluang

\begin{tabular}{|c|c|}
\hline NILAI & PELUANG \\
\hline 1 & 10 tahun sekali \\
\hline 2 & 1 tahun sekali \\
\hline 3 & 3 bulan sekali \\
\hline 4 & 1 bulan sekali \\
\hline 5 & 1 minggu sekali \\
\hline
\end{tabular}

(Sumber : Tarel PT Petrokimia Gresik)

Setelah semua nilai tersebut sudah didapatkan maka selanjutnya dilakukan perhitungan nilai ECR dengan rumus :

ECR : Dampak x Peluang

(Sumber : Tarel PT Petrokimia Gresik)

Setelah mengetahui bobot kriteria yang dipakai dilanjutkan penilaian peralatan dengan menggunakan ECR. Dapat dilihat pada gambar dibawah ini hasil perhitungan ECR :

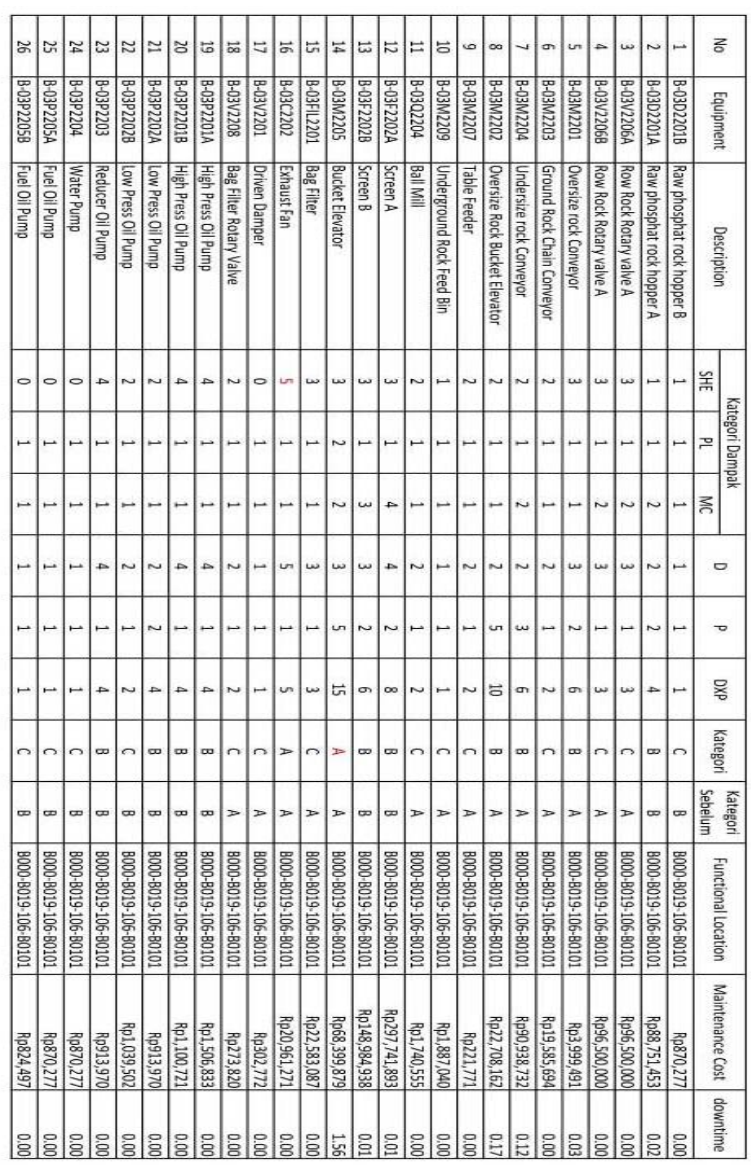

Gambar 3.6 Hasil Penggolongan ECR Functional Location 2 dalam bentuk tabel

Berdasarkan hasil penggolongan ECR peralatan yang berkategori A menjadi berkurang karena penggolongan ECR ini berbeda dengan metode ECR sebelumnya. Metode ECR yang baru menggunakan dampak dan resiko, sedangkan metode yang lama berdasarkan kategori A (matikan pabrik), $\mathrm{B}$ (potong rate produksi), $\mathrm{C}$ (tidak berpengaruh apapun) dan $\mathrm{L}$ (berdampak pada lingkungan pabrik). Metode yang penulis gunakan, lebih akurat karena sudah mempertimbangkan banyak parameter.

\section{Proses Expand Pada Exchenger E-5503}

a. Peralatan Expand

1) Gun Expand

dipergunakan untuk memberi tekanan terhadap benda kerja, benda ini seperti mesin bor akan tetapi bisa maju dan mundur serta bisa diukur dan diatur amperenya yang dihubungkan ke ampere controller. 


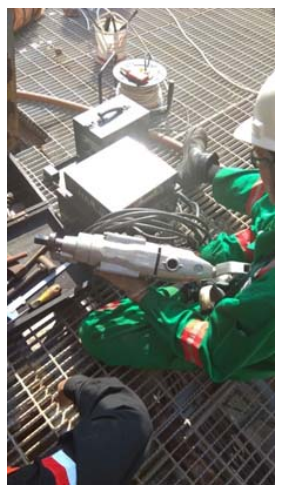

Gambar 3.7 Gun Expand

\section{2) Voltage Controller}

berfungsi untuk penyearah dari sumber listrik ke ampere controller yang kemudian di hubungkan ke gun expand. Sumber listrik yang awalnya arus bolak balik (AC) menjadi arus searah (DC) hal ini dikarenakan agar voltage controller dapat mampertahankan atau memastikan tegangan pada level tertentu sacara otomatis sehingga nyala gun expand yang dihasilkan lebih stabil.

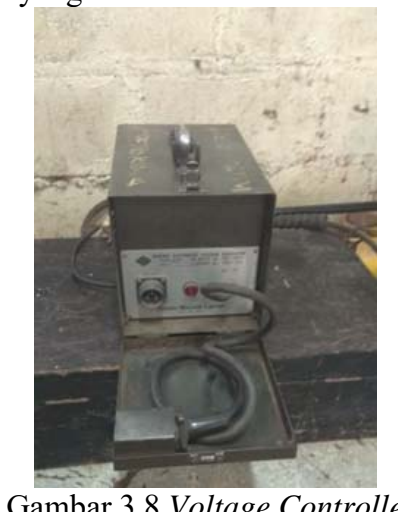

\section{1) Ampere Controller}

Peralatan ini merupakan bantu kerja yang sangat penting di dalam expand tube sheet. Kegunaan ampere control ini mengatur masuknya gun expand terhadap tube sheet karena jika terlalu tinggi ampere maka tube bisa pecah dan jika terlalu kecil tube tidak bisa menempel pada hole tube sheet.

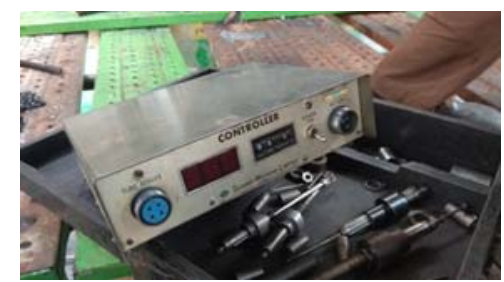

Gambar 3.9 Ampere Controller

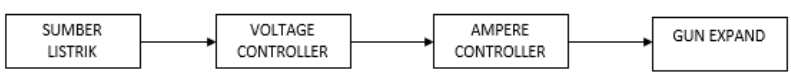

a. Perhitungan Expand

Disini material yang digunakan untuk proses expand pada exchanger E-5503 adalah stainless steel dikarenakan kuat terhadap cairan kimia seperti asam.

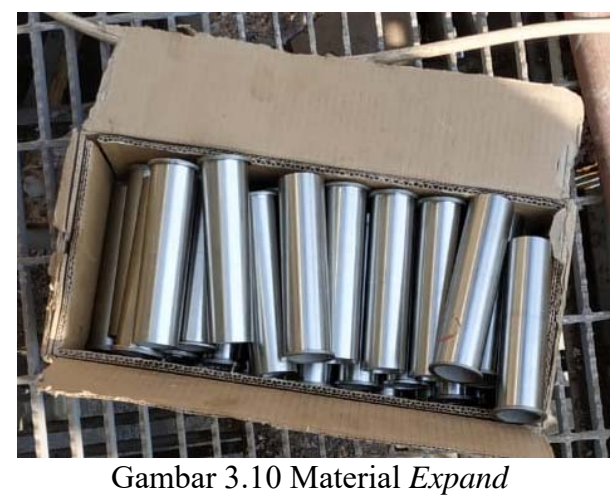

Diketahui :

$\begin{array}{ll}\mathrm{K}=1 \%-5 \% & \mathrm{Di}=32,4 \mathrm{~mm} \\ \text { Do }=36,2 \mathrm{~mm} & \mathrm{H}=36,4 \mathrm{~mm}\end{array}$

Material Stainlees Steel Max 4-5\% expand

(PT Petrokimia Gresik)

$\mathrm{D} 2=\mathrm{K}(\mathrm{Do}+\mathrm{D} 1)+(\mathrm{H}-\mathrm{Do})+\mathrm{D} 1$

$\mathrm{D} 2=1 \%(36,2-32,4)+(36,4-36,2)+32,4$

$=0,01(3,8)+(0,2)+32,2$

$=32,438 \mathrm{~mm}(1 \%)$

$\mathrm{D} 2=2 \%(36,2-32,4)+(36,4-36,2)+32,4$

$=0,02(3,8)+(0,2)+32,2$

$=32,476 \mathrm{~mm}(2 \%)$

$\mathrm{D} 2=3 \%(36,2-32,4)+(36,4-36,2)+32,4$

$=0,03(3,8)+(0,2)+32,2$

$=32,514 \mathrm{~mm}(3 \%)$

D2 $=4 \%(36,2-32,4)+(36,4-36,2)+32,4$

$=0,04(3,8)+(0,2)+32,2$

$=32.552 \mathrm{~mm}(4 \%)$

$\mathrm{D} 2=5 \%(36,2-32,4)+(36,4-36,2)+32,4$

$=0,05(3,8)+(0,2)+32,2$

$=32,59 \mathrm{~mm}(5 \%)$

Dari perhitungan diatas dihasilkan 32,59-32, $4=$ $0,19 \mathrm{~mm}$ dengan ketentuan ampere $1,5 \mathrm{~A}=0,1 \mathrm{~mm}$ 
maka ampere dinaikan 2 kali lipat menjadi 3A dan melakukan expand 2 kali untuk mendapatkan hasil yang maksimal.

Jika sudah mendapatkan hasil yang cukup maka operator bisa menguji dengan cara di masukkan tekanan angin dan gelembung sabun agar operator tau bagian mana yang bocor dan bisa di lakukan expand kembali. Nama test tekanan ini yaitu presstest jika dalam presstest sudah menemukan hasil maka exhanger atau air cooler bisa di tutup kembali dan dijalankan seperti semestinya.

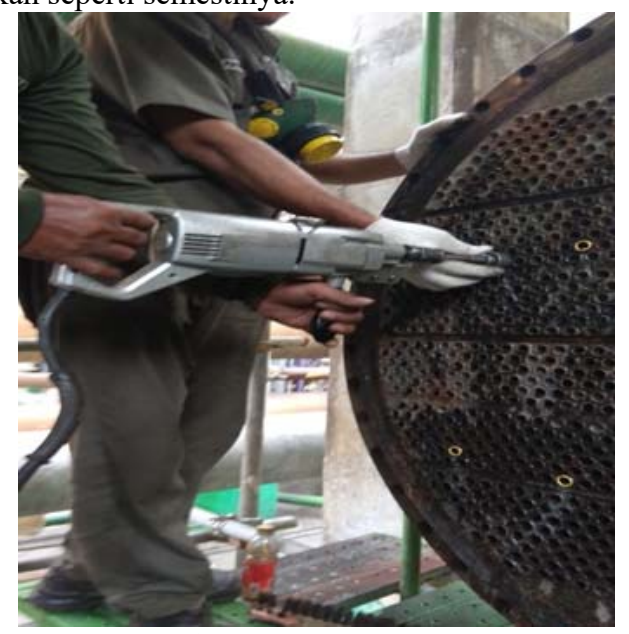

Gambar 3.11 Proses Expand

\section{b. Proses Pelaksanaan Expand}

1) Diambil secara acak 20 tube, kemudian ukur diameter dalam dan luar dan diameter tubesheet (tandai yang telah dipilih dan diukur)

2) Siapkan beberapa peralatan yaitu gun expand, ampere controller, voltage controller.

3) Tentukan posisi expander.

4) Kemudian tentukan amper pada ampere controller.

5) Ukur diameter dalam tube dan record kembali sesuai dengan yang tertulis pada ampere controller dan ulangi pengukuran diameter dalam tube sampai pada diameter yang dikehendaki dan catat besarnya ampere.

6) Dengan mengacu pada ampere yang sudah tercatat, lakukan expand untuk 20 tube dan cek kembali diameter dalam tube sesuai perhitungan.

7) Lakukan expand untuk semua tube dengan menggunakan ampere yang paling tinggi.

8) Lakukan dengan secara berurutan.

9) Lakukan secara bertahap.

\section{IV.PENUTUP}

\section{A. Simpulan}

Setelah melakukan Praktik Industri di PT Petrokimia Gresik dengan pembahasan Penggolongan ECR (Equipment Critically Rating) dan Perawatan Exchanger E-5503 dapat ditarik kesimpulan sebagai berikut:

1. Simpulan penggolongan Equipment Critically Rating.

a. Penggunaan metode pendekatan resiko (dampak dan peluang) dalam penentuan ECR dapat menurunkan peralatan kritis dengan metode sebelumnya.

b. Nilai Safety, Healty, and Environment didapat dari wawancara ke operator peralatan atau mesin.

c. Nilai Production lost didapatan dari data sort maintenance tahun 2010, 2012, 2013, 2014, 2015 , 2016, 2017.

d. Nilai Maintenance Cost didapat dari total biaya yang dihabiskan untuk perbaikan peralatan atau mesin.

e. Nilai Peluang didapat dari berapa kali peralatan atau mesin mati dalam waktu 7 tahun terakhir.

2. Simpulan Proses Expand.

a. Gun Expand, digunakan untuk memberi tekanan terhadap benda kerja serta bisa diukur dan diatur amperenya yang dihubungkan ke ampere controller

b. Voltage Controller, berfungsi untuk penyearah dari sumber listrik ke ampere controller yang kemudian di hubungkan ke gun expand.

c. Ampere Controller, digunakan untuk mengatur masuknya ampere yang masuk ke gun expand yang akan memberi tekanan terhadap benda kerja.

\section{A. Saran}

Saran yang dapat penulis berikan adalah sebagai berikut:

1. Kegiatan pendataan work order (WO) di PT Petrokimia Gresik seharusnya lebih lengkap dalam penyebutan nama atau kode peralatan, karena masih ada beberapa data yang tidak ada keteranganmaintenance peralatan A,B, atau C. hal ini perlu diperbaiki agar dapat menghasilkan data yang valid.

2. Perlu juga dikembangkan metode ECR pada pabrik PA1 di unit 2-5.

3. Lebih memperhatikan tata cara operasional dari mesin-mesin yang ada sesuai dengan standar yang berlaku dan melakukan perawat secara berkala terhadap mesin tersebut agar perfoma kerjanya dapat terjaga atau meningkat khususnya dalam proses 
fabrikasi benda-benda yang lumayan besar seperti heat exchanger agar waktu dalam proses fabrikasinya lebih efisien, karena dalam proses fabrikasi tersebut mesin lebih membutuhkan performa yang besar.

\section{REFERENSI}

[1] Assauri. 2013. Tujuan Maintenance, Surabaya: Erlangga.

[2] Bagian Personalia. 2016. Profil Perusahaan PT Petrokimia Gresik, PT Petrokimia Gresik. Gresik.

[3] Bagian TA dan Reabilitas. 2018. Prosedur Update Equiment Critically Rating, PT Petrokimia Gresik. Gresik.

[4] Bagian Shop Engineering dan QC. 2016. Prosedur Fabrikasi dan Rencana Pemeriksaan Heat Exchanger E 5503, PT Petrokimia Gresik. Gresik.

[5] Dolphina, E. 2011. Laporan Praktik Industri PT Petrokimia Gresik. Madura: Jurusan Teknik Industri Fakultas Teknik Univesitas Trunojoyo.

[6] Incropera, F.P. and D.P. DeWitt. 1981. Fundamentals of Heat Transfer, NewYork: John Wiley \& Sons.

[7] Situmorang, Alam. 2008. Manajemen Industri. Jakarta: ESIS.

[8] Supandi. 1990. Manajemen perawatan industri. Bandung: Ganeca Exact.

[9] Universitas Negeri Surabaya. 2014. Buku Panduan Praktik Industri / Praktik Kerja Lapangan. Surabaya. Unesa University Press. 